\title{
Analysis of Deformation Characteristics of Reverse Slope Under The Influence of Reservoir Water Based On Community Detection
}

\section{Liangfu Xie}

Xinjiang University

jianbin cui ( $\square$ cuijianbin@stu.xju.edu.cn )

Xinjiang University

Yongjun Qin

Xinjiang University

Liewang Qiu

Xinjiang University

\section{Research Article}

Keywords: community detection, reverse slope, deformation characteristic, leader node, reservoir water level

Posted Date: September 20th, 2021

DOl: https://doi.org/10.21203/rs.3.rs-875020/v1

License: (c) (i) This work is licensed under a Creative Commons Attribution 4.0 International License.

Read Full License

Version of Record: A version of this preprint was published at Environmental Earth Sciences on February 1st, 2022. See the published version at https://doi.org/10.1007/s12665-022-10252-9. 


\section{Abstract}

In order to study the deformation characteristics of reverse slope, this paper took the slope of Xiaodongcao as the research object, applied the Louvain community detection algorithm, considered the influence of reservoir water level change, partitioned the slope deformation characteristics. The deformation characteristic zoning result was superimposed with the slope displacement cloud map and three types of geological geometric characteristic factor zoning map obtained by ArcGIS. The results show that $\varangle$ Community detection can quickly identify the closely connected part of slope network, and the specific location of this part is affected by reservoir water. After the community detection result is superimposed with the displacement cloud map, the areas with large deformation and close connection in the slope can be identified. It is found that the community with severe deformation have at least $5 \%$ more displacement and up to $21 \%$ more displacement than that with slow deformation. In addition, the location of leader nodes can be identified, and the number of leader nodes does not exceed $20 \%$ of the total nodes in the community, and its average displacement is at least $10 \%$ more than that of ordinary nodes, up to $36 \%$. After the community detection result is superimposed with the zoning map of slope grade, it can be concluded that the slope grade within the community with severe deformation is greater than $60^{\circ}$, indicating that the larger slope grade is more sensitive to the bank slope deformation.

\section{Introduction}

The toppling instability and failure of reverse slope occur frequently and on a large scale, which not only threatens human production and life, but also causes huge economic losses and even casualties (Froude and Petley, 2018; Huang, 2012). The failure of reverse slope is usually preceded by the beginning of deformation. After a long period of incubation, once it is unstable, it will bring serious harm (Runqiu et al., 2017). Therefore, it is essential to study the deformation characteristics of reverse slope.

At present, there are three main methods to analyze the deformation evolution characteristics of reverse slope: engineering geological analysis method (Qiu et al., 2016; Tu et al., 2007; Xie et al., 2018; Zhao et al., 2020), physical model test method (Adhikary and Dyskin, 2007; Wang and Guo, 2019; Zuo et al., 2005) and numerical simulation method (Dongxing et al., 2005; Peihua et al., 2004; Xu et al., 2005). (Miao et al., 2018; Zheng et al., 2019) used centrifugal test method to study the deformation characteristics of reservoir bank slope model under the influence of water level and the key inducing factors and disaster modes of reverse slope deformation under gravity. Xie et al. (2021) employed the discrete element program UDEC for numerical simulation, studied the deformation characteristics under the influence of different geometric factors, and established the toppling deformation prediction model by using support vector machine. (Lian et al., 2018) based on GIM-DLSM, numerically simulated the jointed rock slope and studied the effects of different parameters such as cohesion, rock block strength and friction angle on the failure mode and deformation of the slope. (Shishu et al., 2015) through on-site investigation and data analysis, put forward the deformation evolution mechanism of bank slope under the action of reservoir water storage, and made a preliminary judgment on the stability of toppling deformation slope by means of numerical simulation. The cycle of these results is long, and the studies require researchers to have 
rich practical experience. Additionally, complex calibration parameters may be carried out in numerical simulation.

In order to make up for the shortcomings of the above research works, this paper utilized the advantage of the community detection technology to quickly find the internal relationship of complex network structure, and applied it to the study of reverse slope deformation. In recent years, community detection technology has developed rapidly, and has been deeply developed and used by many industries. (Hai et al., 2021) applied the complex time series network community detection method to obtain the key characteristics of terrorist attacks. (Jie et al., 2021; Jinjun et al., 2021) used community detection technology to analyze travel demand in the research of urban public transport system. (Keyvanpour et al., 2020) proposed an anomaly recognition method of social network graph based on community detection (AD-C) and applied it to identify anomalies in social networks. (Kamakshi and Sriram, 2020) used the community detection algorithm to form a stable group of vehicles, reduced the system overhead and time delay, and improved the safety, traffic efficiency and convenience of vehicles and roads. In addition, community detection and link prediction technology are also widely employed in the detection and recommendation system of Telecom fraud organizations in the real world(Jia and Rongjian, 2021).

This paper relies on specific engineering examples, utilize community detection technology, employ the actual monitoring data of bank slope, get rid of the limitations of rich practical experience and accurate simulation, and then research the deformation characteristics of reverse slope. According to the deformation characteristics of bank slope, the bank slope is divided into zones, and the internal relations in the complex bank slope network structure are found. The research results can provide reference for practical engineering.

\section{Project Overview}

The object of this study is the Xiaodongcao slope, which is located at the upstream of Xixi River in Zhongliang Township, Wuxi County, Chongqing, and the downstream is $1.2 \mathrm{~km}$ away from the dam site of Zhongliang I Hydropower Station (Zhongliang reservoir). Before the completion of Zhongliang reservoir, the river level was $528.0 \sim 532.5 \mathrm{~m}$. after the construction of the reservoir, the normal water storage is $625.0 \sim 627.0 \mathrm{~m}$, and the water level is nearly $100 \mathrm{~m}$ higher than the original. The bank slope is distributed at an elevation of $526 \sim 1183 \mathrm{~m}$, nearly $700 \mathrm{~m}$ wide, and the slope vegetation is developed. The terrain in the middle and front of the slope is steep, and the terrain slope angle is $45 \sim 68^{\circ}$. The terrain at the rear is relatively gentle, with a topographic slope angle of $11 \sim 18^{\circ}$ and up to $37^{\circ}$ in some sections. The bank slope gullies are relatively developed, with a total of five large gullies developed, all of which flow into Zhongliang reservoir. The gullies are mainly in north-south direction and the gullies are in "V" shape. See Fig. 1 for the overall view and actual deformation of bank slope.

The displacement monitoring system of Xiaodongcao slope mainly includes 22 surface displacement monitoring points, which are evenly distributed in the whole study area, including 17 monitoring points on the slope and 5 outside the slope boundary. The monitoring time of surface displacement is from 
December 2011 to April 2020. According to the layout characteristics of the monitoring system, it is divided into five cross sections and three longitudinal sections. The layout plan of surface displacement detection system is shown in Fig. 2.

\section{Geological Characteristics Of Slope}

In order to study the internal relationship between the geological characteristics of the bank slope and the community detection results, according to the geological survey analysis and topographic survey results, this paper utilizes ArcGIS software to divide the geological characteristics of the bank slope based on three types of geological geometric characteristic factors: elevation, slope and aspect. The partition results are shown in Fig. 3. It can be seen from Fig. 3 that the overall slope of the bank slope is large, the terrain at the top is gentle, and the bank slope tends to west and northwest.

\section{Implementation Process Of Community Detection}

In this paper, the community detection technology is applied to the slope engineering, and the slope is regarded as a complex network structure. Based on the deformation data actually monitored on the slope and considering the influence of reservoir water, the network structure inside the slope is revealed. The community detection flow chart is shown in Fig. 4.

\subsection{Data preprocessing}

The data preprocessing required before using the community detection algorithm mainly includes the processing of nodes and weights, and finally in the form of node-weight-node.

No. 1-22 monitoring points on the Xiaodongcao slope constitute the network structure, and the coordinates of the monitoring points measured for the first time are determined as node coordinates (the displacement deformation difference is 0 ). Based on the displacement deformation difference, which is the difference value measured between this time and last time, a program is written in Python to screen the data under two working conditions of reservoir water change (including reservoir water rise and fall). In the bank slope network structure, the relationship between each two monitoring points is digitized, and this value is called the correlation coefficient $(\mathrm{V})$ between monitoring points, which is the point multiplication value between spatial coordinate vectors (as shown in Eq. (1)).

$$
V_{i j}=\left(x_{i}, y_{i}, z_{i}\right) \mathrm{g}\left(x_{j}, y_{j}, z_{j}\right) \quad(i=1,2, \ldots, 22 ; j=i+1, i+2, \ldots, 22 ; j \leq 22)
$$

where $V_{i j}$ is the correlation coefficient between node i and node j; $\left(x_{i}, y_{i} z_{i}\right)$ and $\left(x_{j i} y_{j}, z_{j}\right)$ are the spatial displacement difference vectors of two nodes.

The final value of correlation coefficient can be divided into zero value and non-zero value. Zero value represents uncorrelation and non-zero value represents correlation. The greater the absolute value of the correlation coefficient, the higher the correlation degree of the two nodes. 
where $V_{a}$ is the average value of correlation coefficient; $N$ is the total number of correlation coefficients.

$\mathrm{W}_{\mathrm{ij}}=\mathrm{V}_{\mathrm{ij}} / \mathrm{V}_{\mathrm{a}}(3)$

where $W_{i j}$ is the weight of the edge between node $i$ and node $j$.

Take the average value of the correlation coefficient $V_{a}$, and divide the correlation coefficient $\left(V_{i j}\right)$ between each two nodes by the average value $\left(V_{a}\right)$ as the weight $(\mathrm{W})$ of the edge between the two nodes.

\subsection{Algorithm selection}

The community detection algorithm in this paper adopts Louvain algorithm,Louvain algorithm (Blondel et al., 2008) performs well in efficiency and performance, which is a heuristic method based on modular optimization. Its optimization goal is to maximize the modularity of the whole community network. Modularity is a standard to measure the division and evaluation of complex network communities, also known as $Q$ value. $Q=0$ means that all observation nodes are divided in the same community. The greater the value of $Q$, the clearer the structure of community division of mobile node set, and the closer the result of community division to the reality(J and M, 2004; Newman, 2006).

\subsection{Detection result}

After the processed data is calculated by the community detection algorithm, the partition result map can be obtained. (Lei, 2014) believed that there is a Pareto principle, which exit differences in the roles of nodes in complex networks. Leader nodes play a decisive role in the formation communities. Such nodes are only about $20 \%$ or less. They are more authoritative, central and core. By analyzing the detection results and the measured node deformation data, this paper can analyze the main control nodes in the community, which are the leader nodes.

\section{Zoning Characteristics Of Bank Slope Under Reservoir Water}

In this paper, under the two working conditions of bank slope reservoir water level decline and rise, the community detection algorithm is applied to process displacement data, and the deformation characteristic zoning of bank slope is obtained. Based on displacement cloud map analyzed by ArcGIS, the relationship between deformation characteristic zoning and bank slope displacement is gained, and the leader nodes existing in the community are further analyzed. Additionally, based on the zoning of geological characteristics, the relationships between community detection results and three types of geological geometric factors are researched.

\subsection{Reservoir water level decline}

According to the decline degree of reservoir water level, the community detection results can be divided into two parts. 
Taking the decline of water level in bank slope reservoir as the standard, the monitoring data are processed, and the results are shown in Fig. 5. According to the zoning results, the 22 monitoring points can be divided into two communities, the first community is the blue monitoring point, and the second community is the yellow monitoring point. When the falling range of reservoir water level is $0 \sim 2 \mathrm{~m}$ (excluding 0 ), the first community is mainly distributed at the upper and lower edges of the bank slope, and the second community is mainly distributed at the middle and upper parts of the bank slope. When the falling range of reservoir water level is $2 \sim 6 \mathrm{~m}$, the first community is mainly distributed in the middle and right of the bank slope, and the second community is mainly distributed on the left of the bank slope.

The results after superimposing the community detection results with the bank slope displacement nephogram are shown in Fig. 6. Community detection can quickly identify the large deformation and closely related parts on the bank slope and classify them as the same community. The displacement curve of monitoring points is drawn according to the community detection results, as shown in Fig. 7. When the reservoir water level drops, the curves of the second community are slightly higher than the first community, indicating that the bank slope deformation in the second community is more severe than that in the first community. What's more, we can also identify the leader nodes, which play the main control role in the community. Combining Fig. 6 and Fig. 7, we can see the specific locations and deformation values of the leader nodes. When the decline range of reservoir water level is $0 \sim 2 \mathrm{~m}$ (excluding 0 ), the leader nodes in the first community are No. 12 and No. 21, and the leader nodes in the second community are No. 7 and No. 9. When the falling range of reservoir water level is $2 \sim 6 \mathrm{~m}$, the leader nodes in the first community are No. 9 and No. 21, and the leader nodes in the second community are No. 17 and No. 20. The number of leader nodes shall not be greater than $20 \%$ of the total number of nodes in the same community. The average displacement of nodes in the community where the reservoir water drops is shown in Table 1. After calculation, the average displacement of leader nodes in the same community is $22 \sim 36 \%$ more than that of ordinary nodes, and the overall displacement of the second community is $17.5 \sim 21.2 \%$ more than that of the first community.

Table 1 Average displacement of nodes in community with reservoir water decline

\begin{tabular}{|c|c|c|c|c|c|}
\hline \multirow{2}{*}{$\begin{array}{l}\text { Reservoir } \\
\text { water } \\
\text { condition }\end{array}$} & \multirow[t]{2}{*}{$\begin{array}{l}\text { Community } \\
\text { order }\end{array}$} & \multicolumn{2}{|c|}{$\begin{array}{l}\text { Average } \\
\text { displacement }\end{array}$} & \multirow{2}{*}{$\begin{array}{l}\text { surplus } \\
\text { displacement of } \\
\text { leader node } \% \bigotimes\end{array}$} & \multirow{2}{*}{$\begin{array}{l}\text { surplus displacement } \\
\text { of the second } \\
\text { community } \\
\text { ॠष }\end{array}$} \\
\hline & & $\begin{array}{l}\text { leader } \\
\text { node } \\
(\mathrm{mm})\end{array}$ & $\begin{array}{l}\text { common } \\
\text { node } \\
(\mathrm{mm})\end{array}$ & & \\
\hline \multirow{2}{*}{$\begin{array}{l}\text { declines by } \\
0 \sim 2 \mathrm{~m}\end{array}$} & first & 5.9 & 3.8 & 36 & \multirow[t]{2}{*}{21} \\
\hline & second & 6.3 & 4.8 & 24 & \\
\hline \multirow{2}{*}{$\begin{array}{l}\text { declines by } \\
2 \sim 6 \mathrm{~m}\end{array}$} & first & 6.9 & 5.0 & 28 & \multirow[t]{2}{*}{18} \\
\hline & second & 7.4 & 5.8 & 22 & \\
\hline
\end{tabular}


Comparing the community detection results with the elevation, slope and aspect zoning results, it is shown that the community detection results have a great relationship with the slope. According to the superposition results (Fig. 8), the slope within the second community accounts for a large proportion of $63 \sim 90^{\circ}$, especially $72 \sim 90^{\circ}$, indicating that the slope in the second community is steep and prone to deformation.

\subsection{Reservoir water level raise}

According to the rising degree of reservoir water level, the community detection results can be divided into two parts.

Taking the rise of reservoir water level on the bank slope as the standard, the monitored data is processed, and the results are shown in Fig. 9. According to the zoning results, the 22 monitoring points can be divided into two communities, the first community is the blue monitoring point, and the second community is the yellow monitoring point. When the rising range of reservoir water level is $0 \sim 6 \mathrm{~m}$ (excluding 0 ), the first community is mainly distributed at the top and middle lower part of the bank slope, and the second community is mainly distributed at the middle upper part of the bank slope. When the rising range of reservoir water level is $6 \sim 23 \mathrm{~m}$, the first community is mainly distributed in the middle and right of the bank slope, and the second community is mainly distributed at the edge of the bank slope.

The results after overlapping the community detection results with the bank slope displacement nephogram are shown in Fig. 10. According to the results, the part with severe deformation and close connection on the bank slope is also within the scope of the second community, which is the same as the water level decline condition of the reservoir on the bank slope. Combining Fig. 10 and Fig. 11, we can see the specific position and deformation value of the leader nodes. When the rising range of reservoir water level is $0 \sim 6 \mathrm{~m}$ (excluding 0), the leader nodes in the first community are No. 1 and No. 13, and the leader nodes in the second community are No. 9 and No. 12. When the rising range of reservoir water level is $6 \sim$ $23 \mathrm{~m}$, the leader nodes in the first community are No. 5 and No.11, and the leader nodes in the second community are No. 8 and No. 12. The number of leader nodes is no more than $20 \%$ of the total number of nodes in the community. The average displacement of nodes in the community where the reservoir water raises is shown in Table 2. After calculation, the average displacement of leader nodes is $11 \sim 17 \%$ more than that of ordinary nodes, and the overall displacement of the second community is $5 \sim 18.1 \%$ more than that of the first community.

Table 2 Average displacement of nodes in community with reservoir water raise 


\begin{tabular}{|c|c|c|c|c|c|}
\hline \multirow{2}{*}{$\begin{array}{l}\text { Reservoir } \\
\text { water } \\
\text { condition }\end{array}$} & \multirow[t]{2}{*}{$\begin{array}{l}\text { Community } \\
\text { order }\end{array}$} & \multicolumn{2}{|c|}{$\begin{array}{l}\text { Average } \\
\text { displacement }\end{array}$} & \multirow{2}{*}{$\begin{array}{l}\text { surplus } \\
\text { displacement of } \\
\text { leader node } \% \bigotimes\end{array}$} & \multirow{2}{*}{$\begin{array}{l}\text { surplus displacement } \\
\text { of the second } \\
\text { community } \\
\text { ४४ }\end{array}$} \\
\hline & & $\begin{array}{l}\text { leader } \\
\text { node } \\
(\mathrm{mm})\end{array}$ & $\begin{array}{l}\text { common } \\
\text { node } \\
(\mathrm{mm})\end{array}$ & & \\
\hline \multirow{2}{*}{$\begin{array}{l}\text { raises by } 0 \sim 6 \\
\mathrm{~m}\end{array}$} & first & 5.2 & 4.3 & 17 & \multirow[t]{2}{*}{18} \\
\hline & second & 5.9 & 5.2 & 12 & \\
\hline \multirow{2}{*}{$\begin{array}{l}\text { raises by } \\
6 \sim 23 \mathrm{~m}\end{array}$} & first & 7.2 & 6.0 & 17 & \multirow[t]{2}{*}{5} \\
\hline & second & 7.2 & 6.4 & 11 & \\
\hline
\end{tabular}

The community detection results under the condition of rising reservoir water level are superimposed with the bank slope zoning results, as shown in Fig. 12. According to the superposition results, it is basically consistent with the results obtained under the condition of reservoir water level decline. the slope within the second community accounts for a large proportion of $63 \sim 90^{\circ}$, indicating that the slope in the second community is steep and prone to deformation.

\section{Conclusion}

In this paper, the actual monitoring data of 22 monitoring points on the bank slope is processed by using the Louvain community detection algorithm. Considering the influence of the rise and decline of reservoir water level on the bank slope, the deformation characteristics zoning of the bank slope under the action of reservoir water are finally obtained. After superimposing the deformation zoning with the bank slope displacement cloud map and the zoning maps of three types of geological geometric characteristic factors respectively, it is found that the bank slope network structure has the following relationship with displacement and the slope区

(1) Community detection technology can identify the closely connected part of the bank slope network according to the deformation characteristics of the bank slope. Under the action of reservoir water, the specific location of this part will change.

(2) After superimposing the community detection result with the bank slope displacement nephogram, the community detection technology can find the parts with large internal deformation and close connection with the bank slope, and reveal that the displacement of the community with severe deformation is at least $5 \%$ more than that of the community with slow deformation, and the maximum displacement can be up to $21 \%$. The location of leader nodes in the community can also be identified. The number of leader nodes is no more than $20 \%$ of the total nodes in the community. The average displacement of leader nodes is at least $10 \%$ more than that of ordinary nodes, up to $36 \%$.

(3) After the community detection result is superimposed with the zoning maps of three types of geological geometric characteristic factors, there is a connection between the community detection result 
and the slope zoning result. Comparing this connection with the bank slope displacement cloud map, it is found that the slope with severe deformation is greater than $60^{\circ}$, indicating that the larger slope is more sensitive to the bank slope deformation.

\section{Declarations}

Acknowledgements: This project was supported by the National Natural Science Foundation of China $(52068066,51908482)$ the Scientific Research Program of the Higher Education Institution of Xinjiang (XJEDU2018Y008).

\section{References}

1. Adhikary DP, Dyskin AV (2007) Modelling of Progressive and Instantaneous Failures of Foliated Rock Slopes. Rock Mech Rock Eng 40:349-362

2. Blondel VD, Guillaume J-L, Lambiotte R, Lefebvre E (2008) Fast unfolding of communities in large networks. Journal of Statistical Mechanics: Theory and Experiment 2008

3. Dongxing C, Daan L, Enbao D, Weihong C, Wei P, Yanhui L, Huafeng G (2005) Three-dimension Numerical Simulation of Deformation Characteristics of Toppling Rock Slope-Case Study for a Slope at LongTan Hydropower Station. Journal of Engineering Geology:222-226

4. Froude MJ, Petley DN (2018) Global fatal landslide occurrence from 2004 to 2016. Nat Hazards Earth Syst Sci 18:2161-2181

5. Hai QH, Hong DZ, Jia LH, Jun H, Qun S, Li G (2021) Research on historical phase division of terrorism: An analysis method by time series complex network. Neurocomputing 420

6. Huang R (2012) Mechanisms of large-scale landslides in China. Bull Eng Geol Env 71:161-170

7. J NME, M G (2004) Finding and evaluating community structure in networks. Physical review E, Statistical, nonlinear, and soft matter physics 69

8. Jia W, Rongjian M (2021) A Regularized Convex Nonnegative Matrix Factorization Model for signed network analysis. Social Network Analysis and Mining 11

9. Jie S, Liye Z, Zheng Q, Azfar RM (2021) A spatiotemporal dynamic analyses approach for dockless bike-share system. Computers, Environment and Urban Systems 85

10. Jinjun $T$, Jian $L$, Fang $L$, Jingjing $H$, Yinhai W (2021) Multi-community passenger demand prediction at region level based on spatio-temporal graph convolutional network. Transportation Research Part C 124

11. Kamakshi S, Sriram VSS (2020) Modularity based mobility aware community detection algorithm for broadcast storm mitigation in VANETs. Ad Hoc Networks 104

12. Keyvanpour MR, Shirzad MB, Ghaderi M (2020) AD-C: a new node anomaly detection based on community detection in social networks. International Journal of Electronic Business 15

13. Lei P (2014) Research On Several Community Detection Algorithms. Doctor, Nanjing University 
14. Lian J-J, Li Q, Deng X-F, Zhao G-F, Chen Z-Y (2018) A Numerical Study on Toppling Failure of a Jointed Rock Slope by Using the Distinct Lattice Spring Model. Rock Mechanics and Rock Engineering 51

15. Miao F-S, Wu Y-P, Xie Y-H, Li Y-N, Li L-W (2018) Centrifugal test on retrogressive landslide influenced by rising and falling reservoir water level. Yantu Lixue/Rock Soil Mechanics 39:605-613. doi:10.16285/j.rsm.2016.2518

16. Newman MEJ (2006) Modularity and community structure in networks. Proceedings of the National Academy of Sciences 103

17. Peihua X, Jianping C, Runqiu H, Ming Y (2004) Analyses of 3D numerical simulation of toppling deformation mechanism of Jiefanggou left slope in Jingping Step 1 hydropower station. Coal Geology \& Exploration:40-43

18. Qiu J, Ren G-M, Wang Y-N (2016) Characteristics of forming conditions and development scale of toppling in anti-dip and dip stratified slopes. Yantu Lixue/Rock Soil Mechanics 37:513-524 and 532. doi:10.16285/j.rsm.2016.S2.066

19. Runqiu H, Yusheng L, Ming Y (2017) The implication and evaluation of toppling failure in engineering geology practice. Journal of Engineering Geology 25:1165-1181

20. Shishu Z, Xiangjun P, Jianqiao M, Renkun W, Congyan R, Changwu C, Panfeng L, Xiaoping Z (2015) Evolution mechanisms analysis of Xingguangsanzu toppling deformation bodies under condition of impound water of Xiluodu hydropower station. Chin J Rock Mechan Eng 34:4091-4098

21. Tu X, Dai F, Lu X, Zhong H (2007) Toppling and stabilization of the intake slope for the Fengtan Hydropower Station enlargement project, Mid-South China. Eng Geol 91:152-167

22. Wang J-J, Guo J-J (2019) Mechanism and stability of secondary toppling of counter-tilt rock slopes. Yantu Gongcheng Xuebao/Chinese Journal of Geotechnical Engineering 41:1619-1627. doi:10.11779/CJGE201909005

23. Xie L, Yan E, Wang J, Lu G, Yu G (2018) Study on evolutionary characteristics of toppling deformation of reverse-dip layered rock slope based on surface displacement monitoring data. Environmental Earth Sciences 77

24. Xie LF, Ge Y, Zhang JQ, Tan SL, Wang B, Yan EC, Qin YJ, Wang JH, Shi C, Yu GM (2021) Geometric model for toppling-prone deformation of layered reverse-dip slope. Nat Hazards 106:1879-1894. doi:10.1007/s11069-021-04516-z

25. Xu P-H, Chen J-P, Huang R-Q, Yan M (2005) Stability analysis of left high slope at Jiefanggou under the condition of storing water for a certain hydropower station. Yantu Lixue/Rock Soil Mechanics 26:827-832

26. Zhao W, Zhang C, Ju N (2020) Identification and zonation of deep-seated toppling deformation in a metamorphic rock slope. Bulletin of Engineering Geology and the Environment

27. Zheng D, Wang Q, Mao F, Su H (2019) Centrifuge model test study on key hazard-inducing factors of deep toppling deformation and disaster patterns of counter-tilt layered rock slopes. Yanshilixue Yu 
Gongcheng Xuebao/Chinese Journal of Rock Mechanics Engineering 38:1954-1963. doi:10.13722/j.cnki.jrme.2018.1484

28. Zuo B-C, Chen C-X, Liu X-W, Shen Q (2005) Modeling experiment study on failure mechanism of counter-tilt rock slope. Yanshilixue Yu Gongcheng Xuebao/Chinese Journal of Rock Mechanics Engineering 24:3505-3511

\section{Figures}

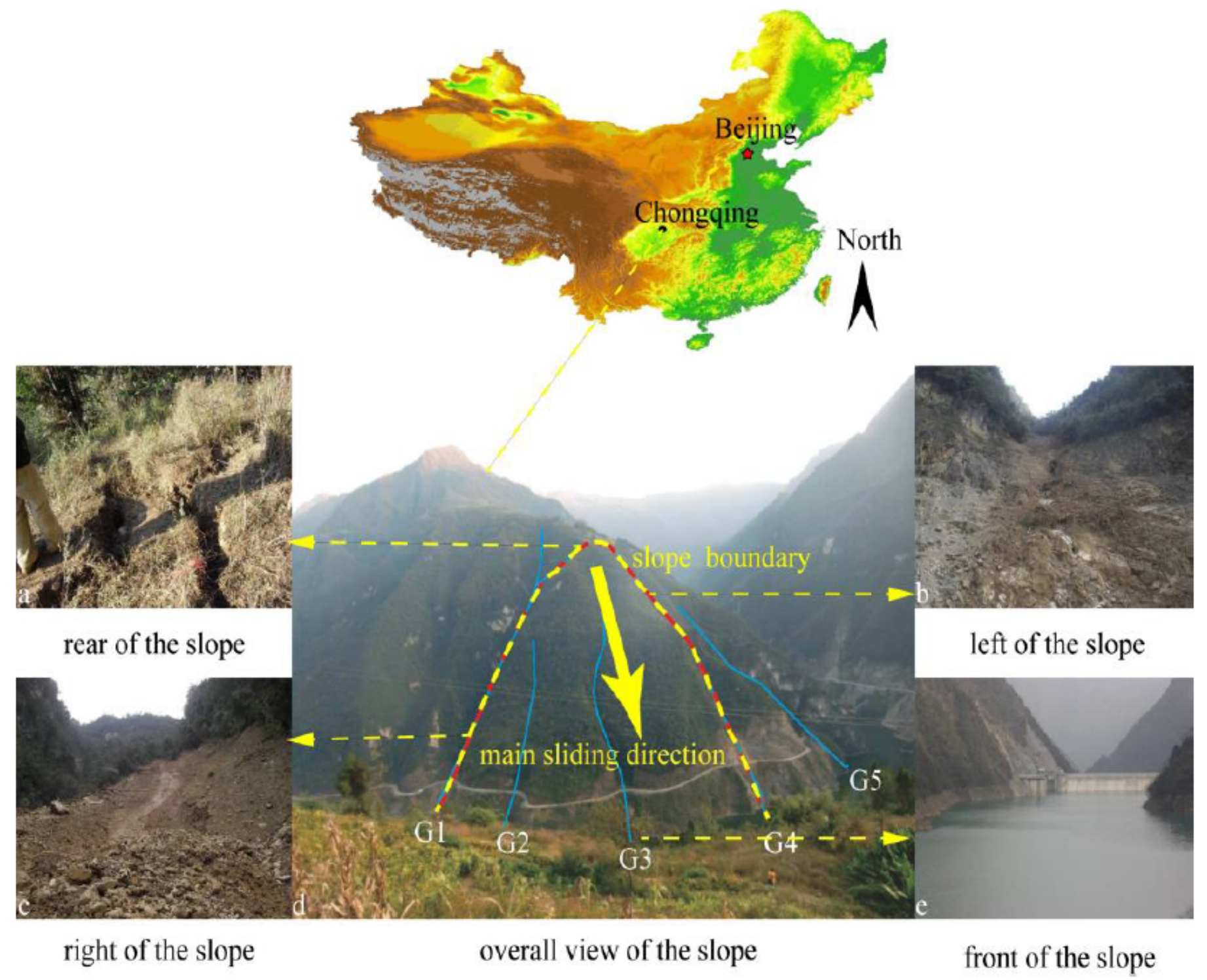

\section{Figure 1}

Overall view and deformation of bank slope 


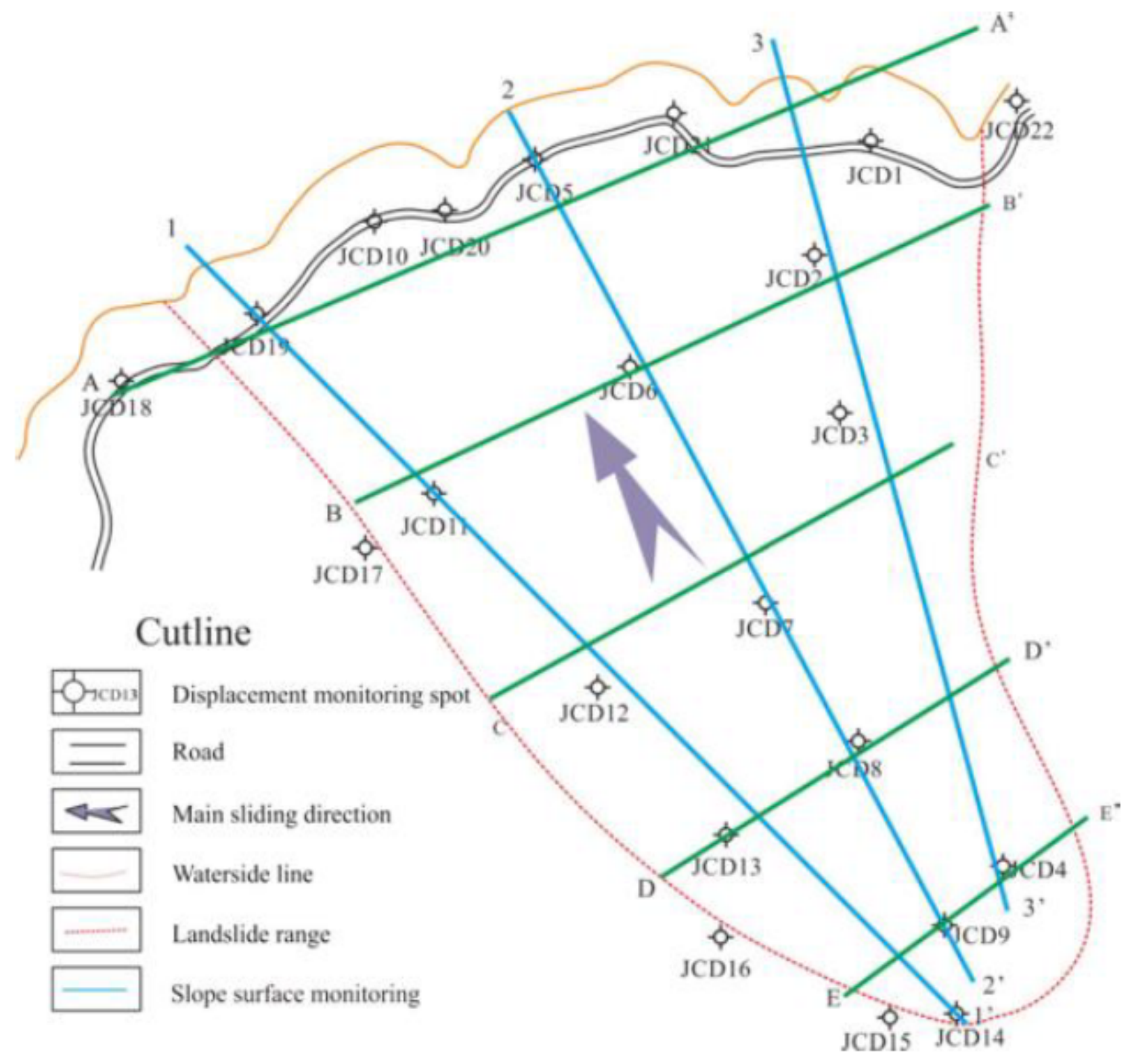

Figure 2

Layout plan of surface displacement monitoring system
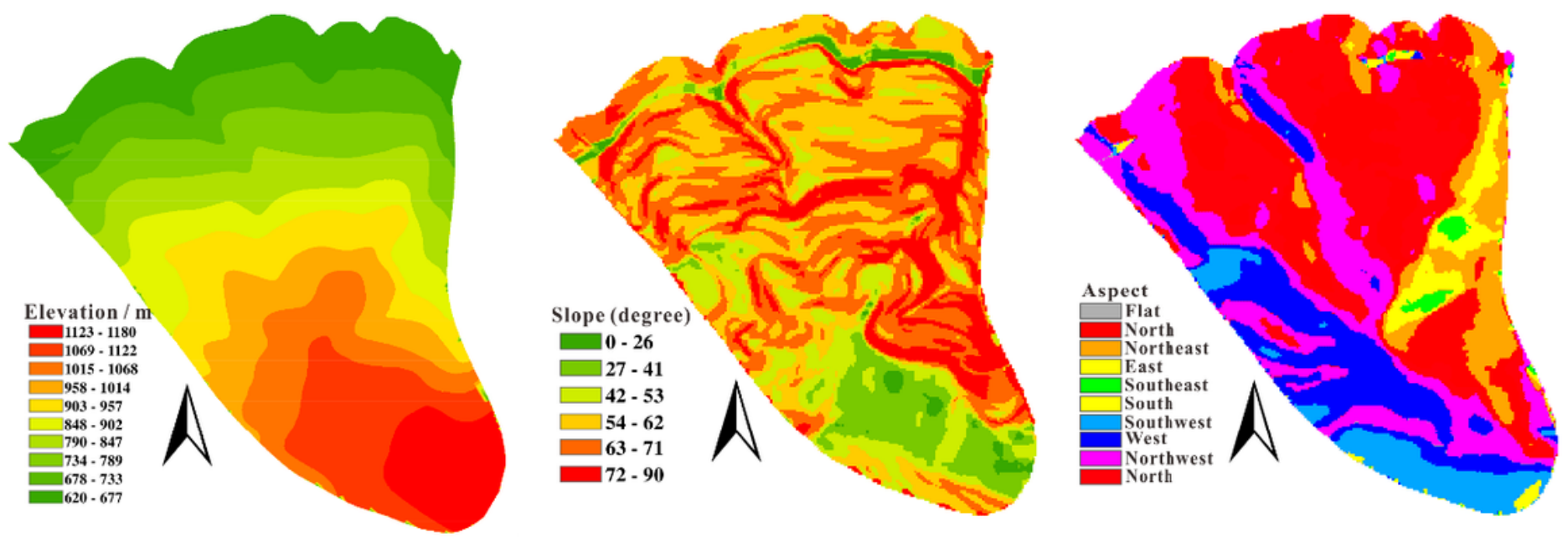
Figure 3

Elevation, slope and aspect zoning maps

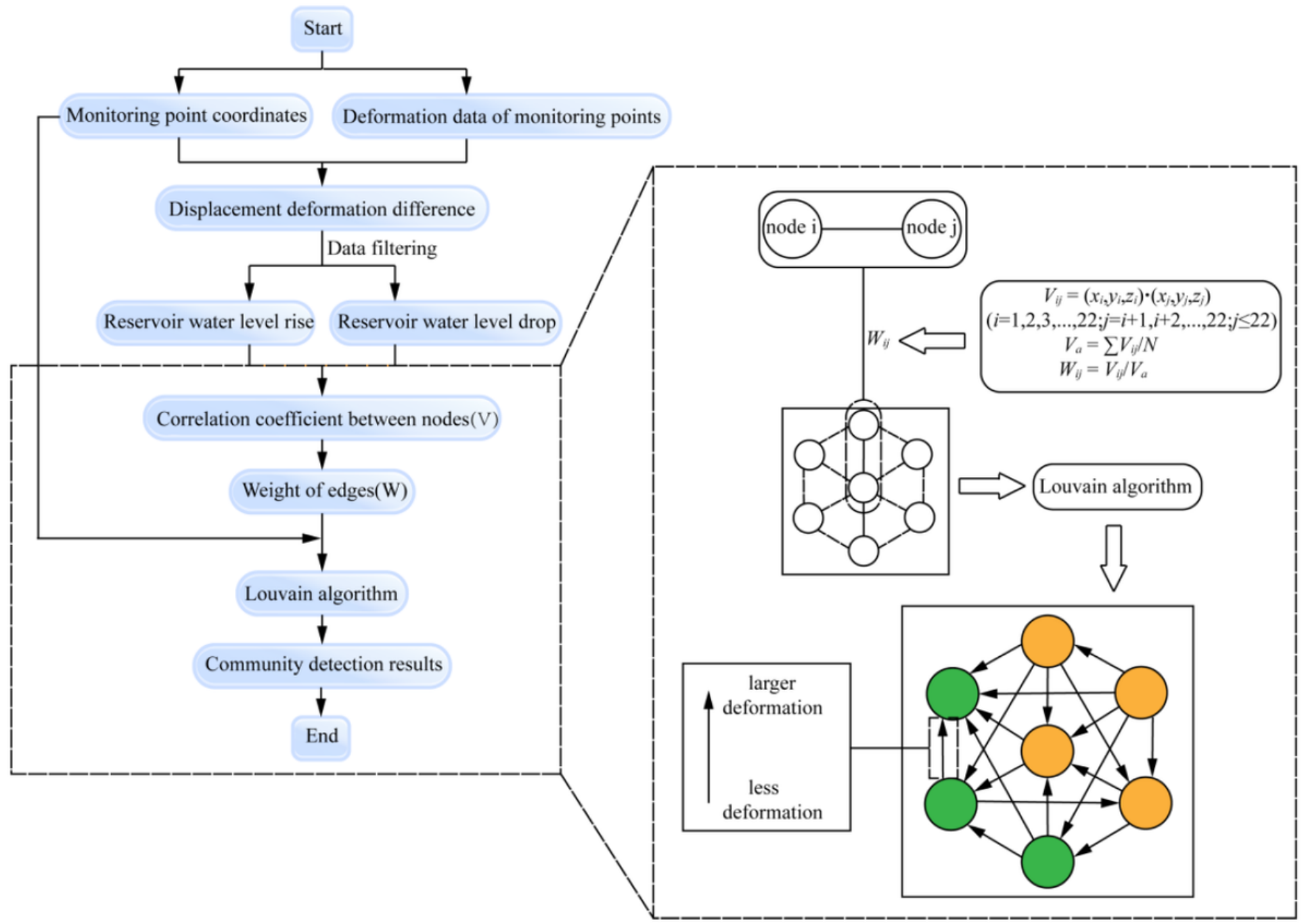

Figure 4

Flow chart of community detection 


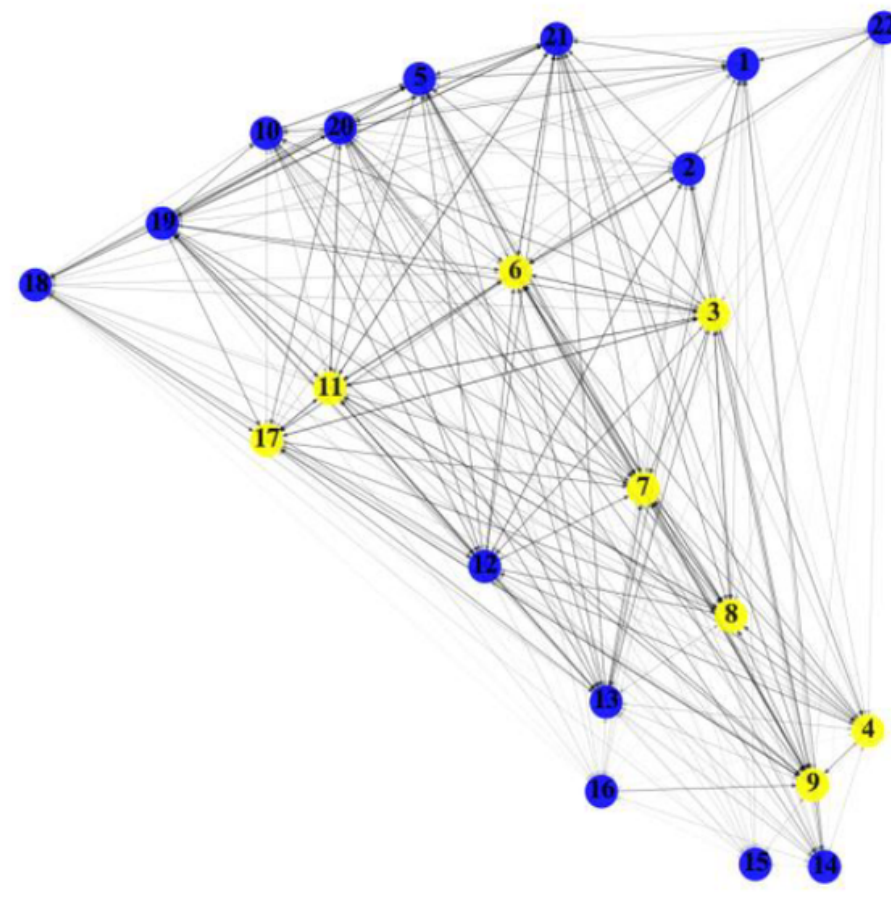

(a) Reservoir water declines by $0 \sim 2 \mathrm{~m}$

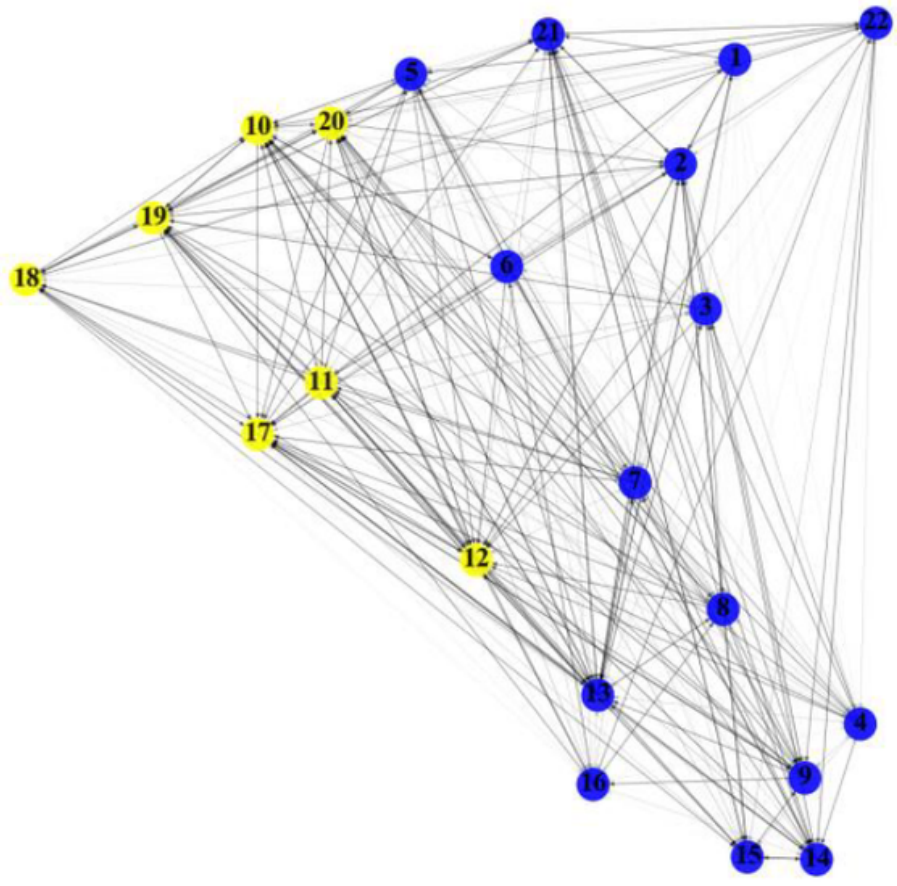

(b) Reservoir water declines by $2 \sim 6 \mathrm{~m}$

Figure 5

Community detection results of reservoir water level decline

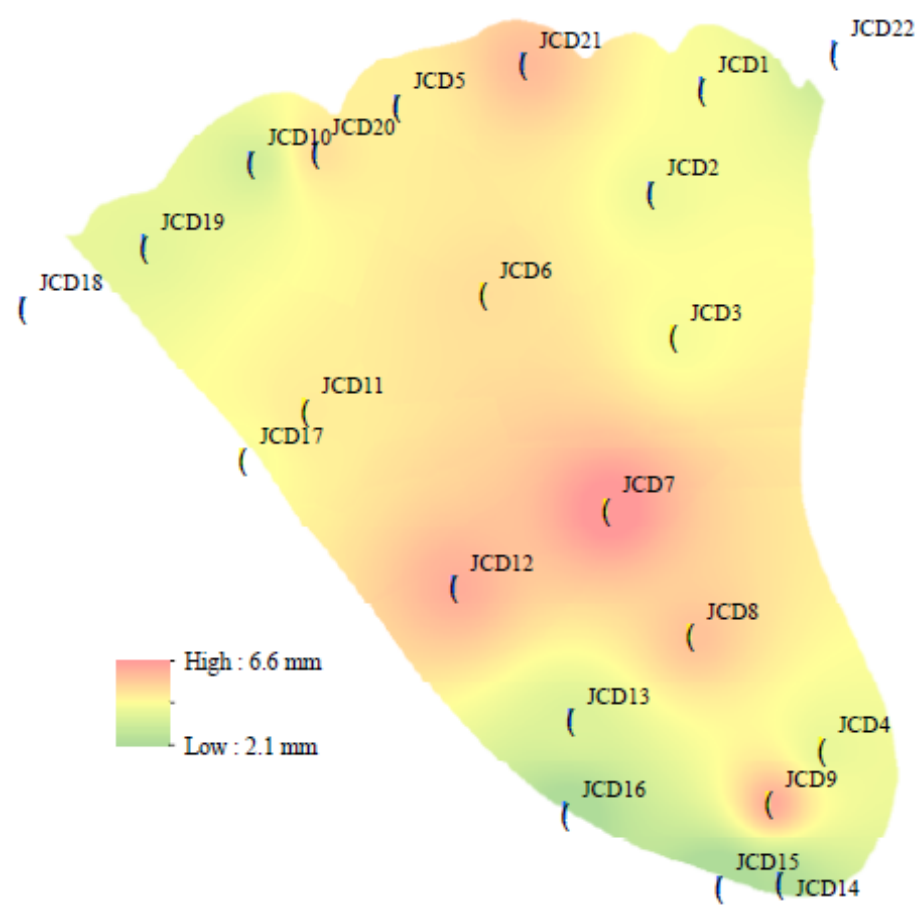

(a) Reservoir water declines by $0 \sim 2 \mathrm{~m}$

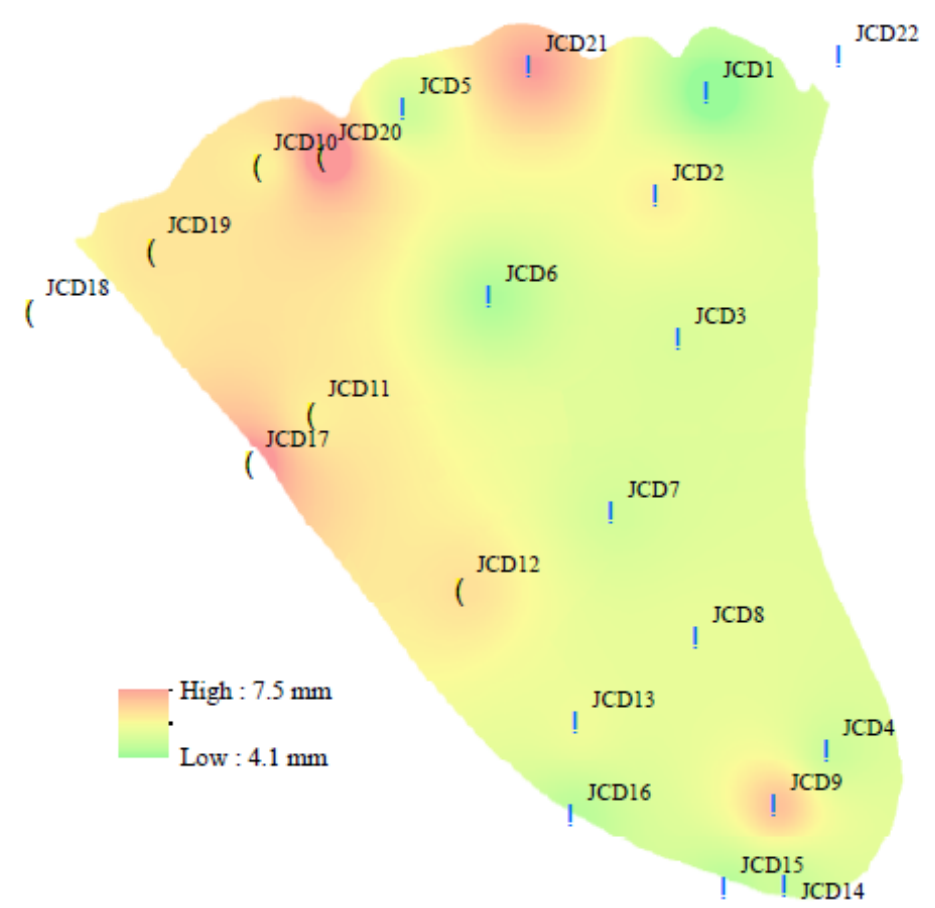

(b) Reservoir water declines by $2 \sim 6 \mathrm{~m}$

Figure 6 


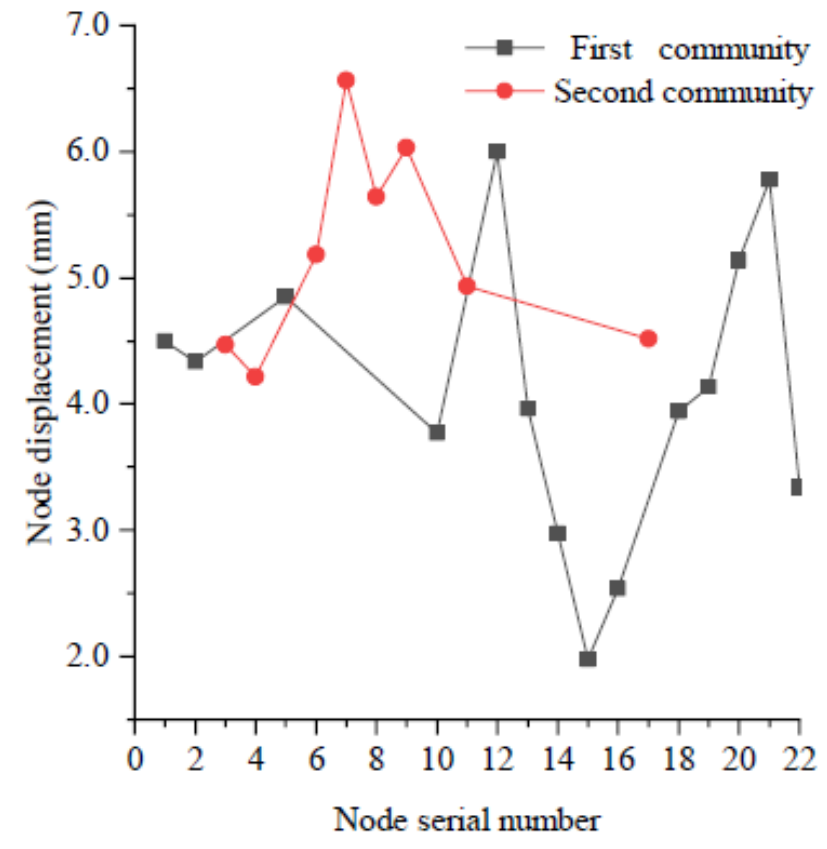

(a) Reservoir water declines by $0 \sim 2 \mathrm{~m}$

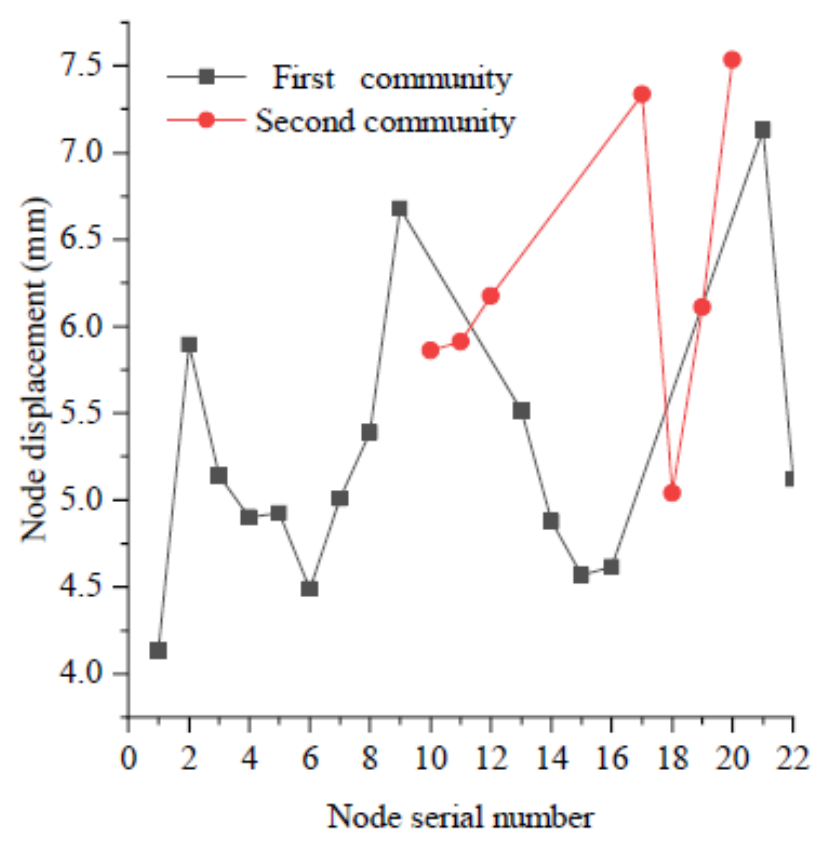

(b) Reservoir water declines by $2 \sim 6 \mathrm{~m}$

\section{Figure 7}

Average displacement diagram of monitoring points for reservoir water level decline

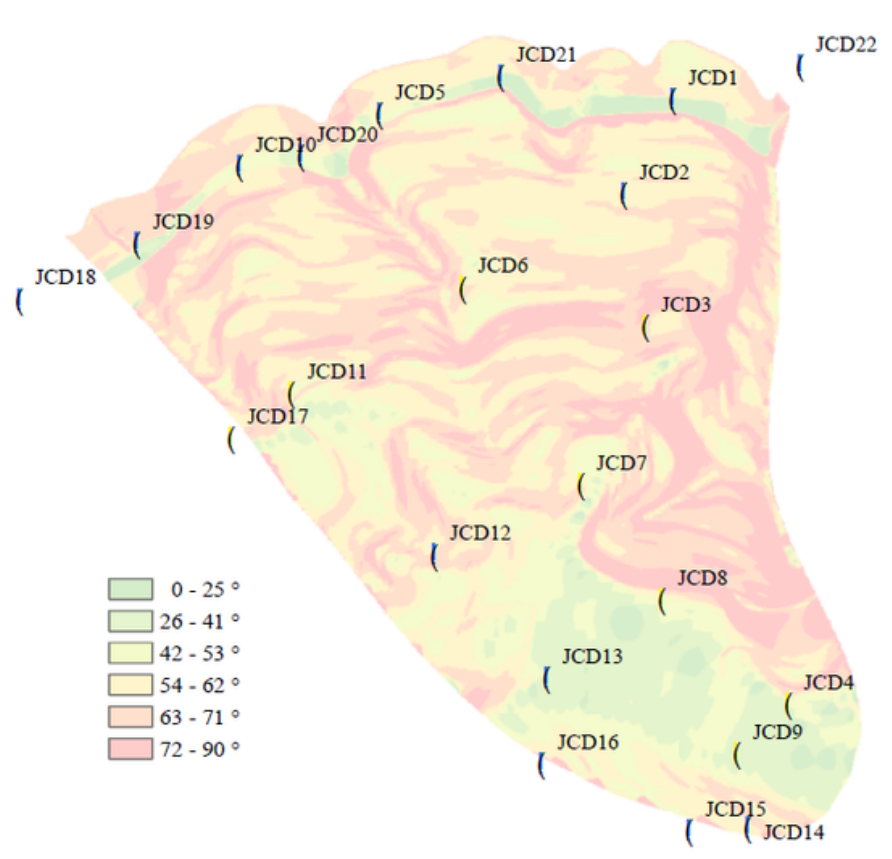

(a) Reservoir water declines by $0 \sim 2 \mathrm{~m}$

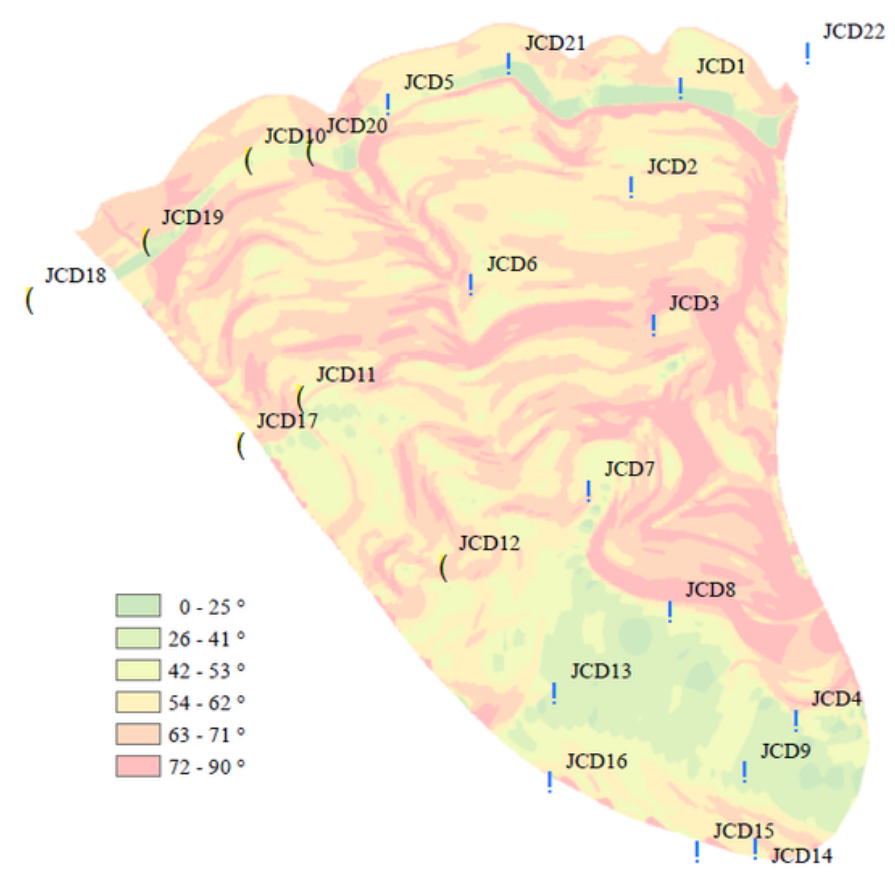

(b) Reservoir water declines by $2 \sim 6 \mathrm{~m}$

\section{Figure 8}


Superposition diagram of decline slope of reservoir water level and detection results

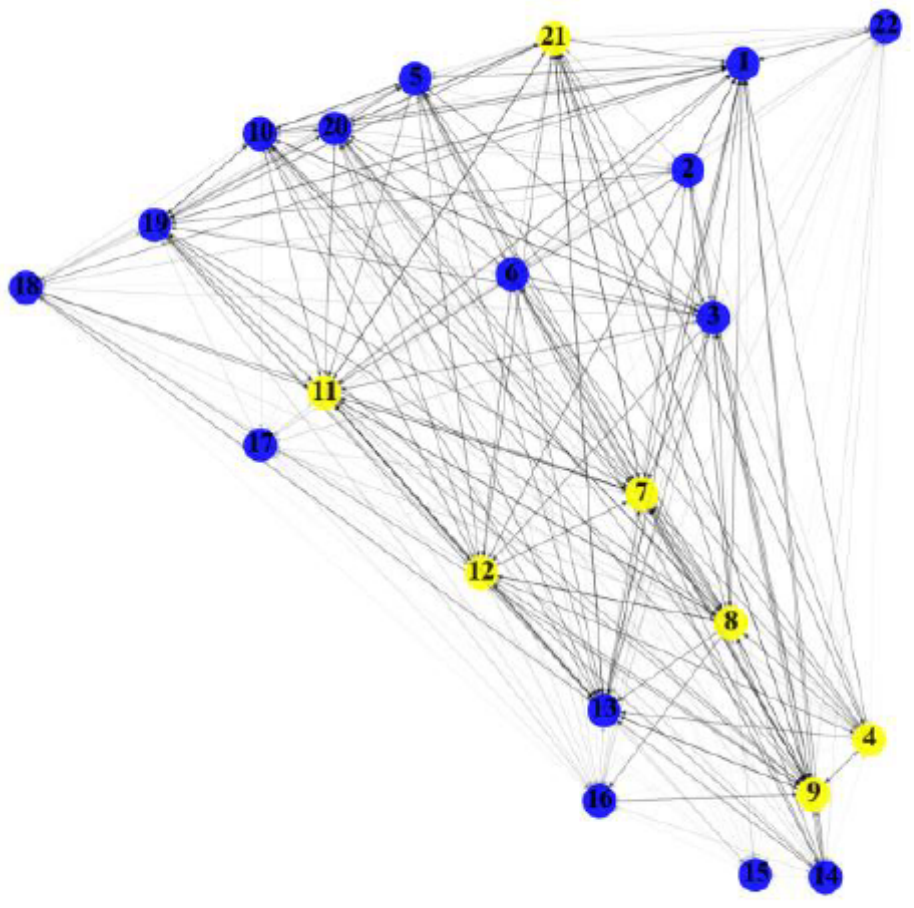

(a) Reservoir water rises by $0 \sim 6 \mathrm{~m}$

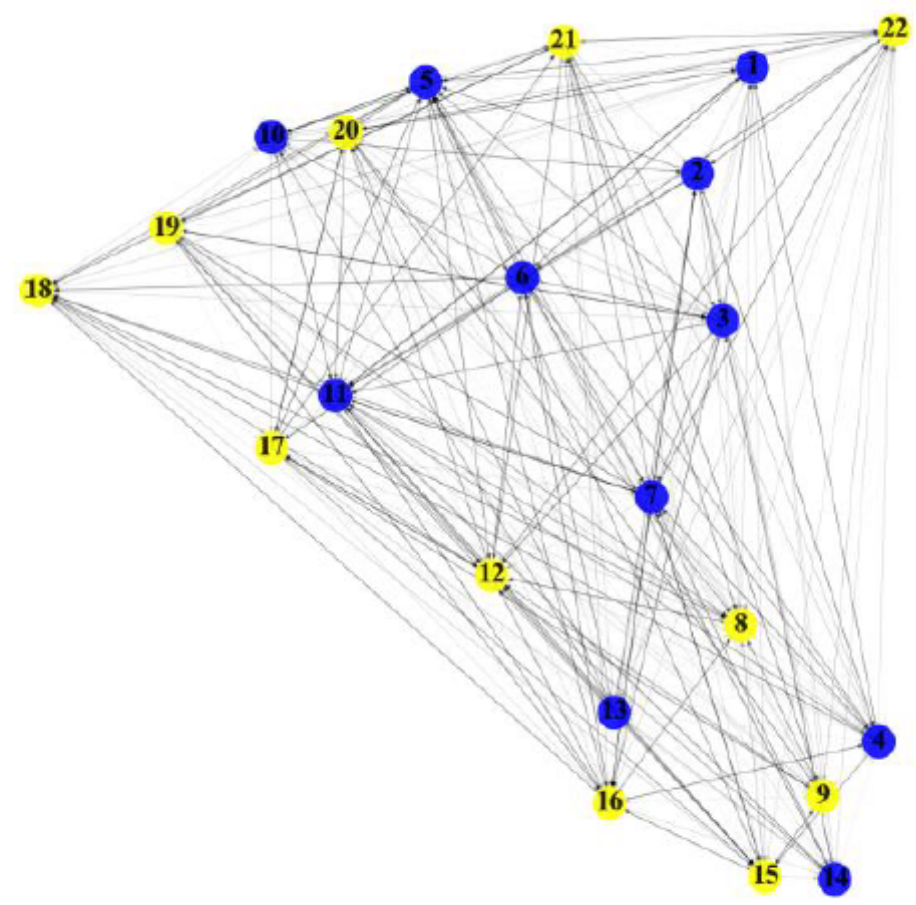

(b) Reservoir water rises by $6 \sim 23 \mathrm{~m}$

\section{Figure 9}

Community detection results of reservoir water level raise

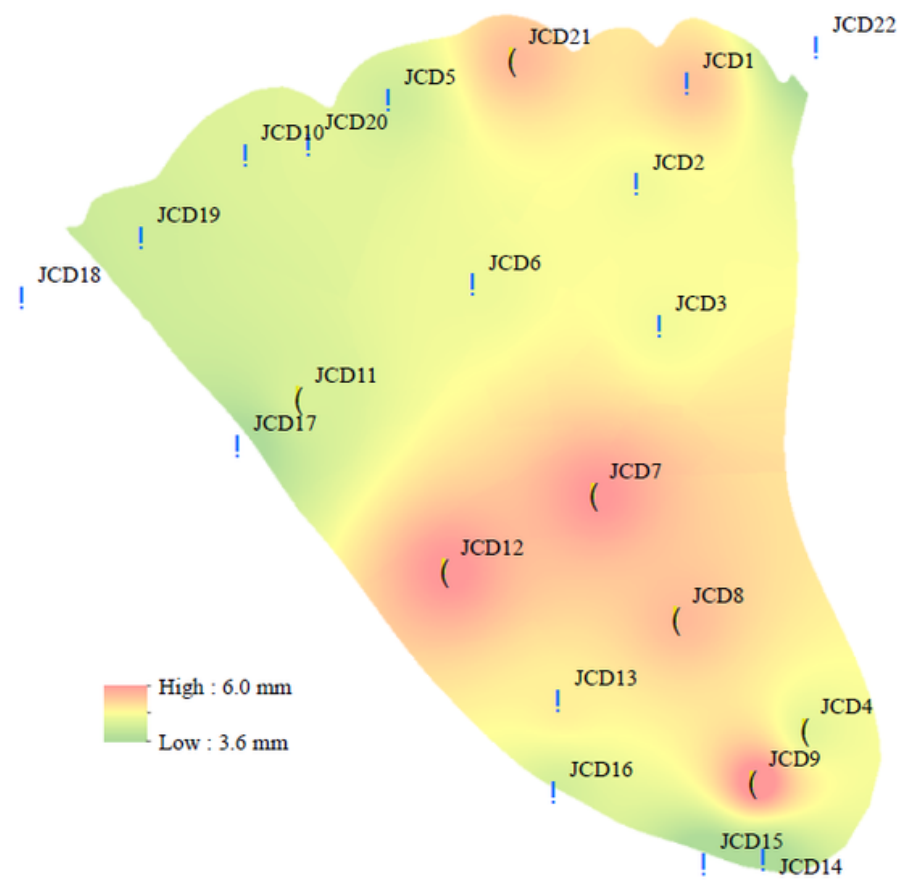

(a) Reservoir water rises by $0 \sim 6 \mathrm{~m}$

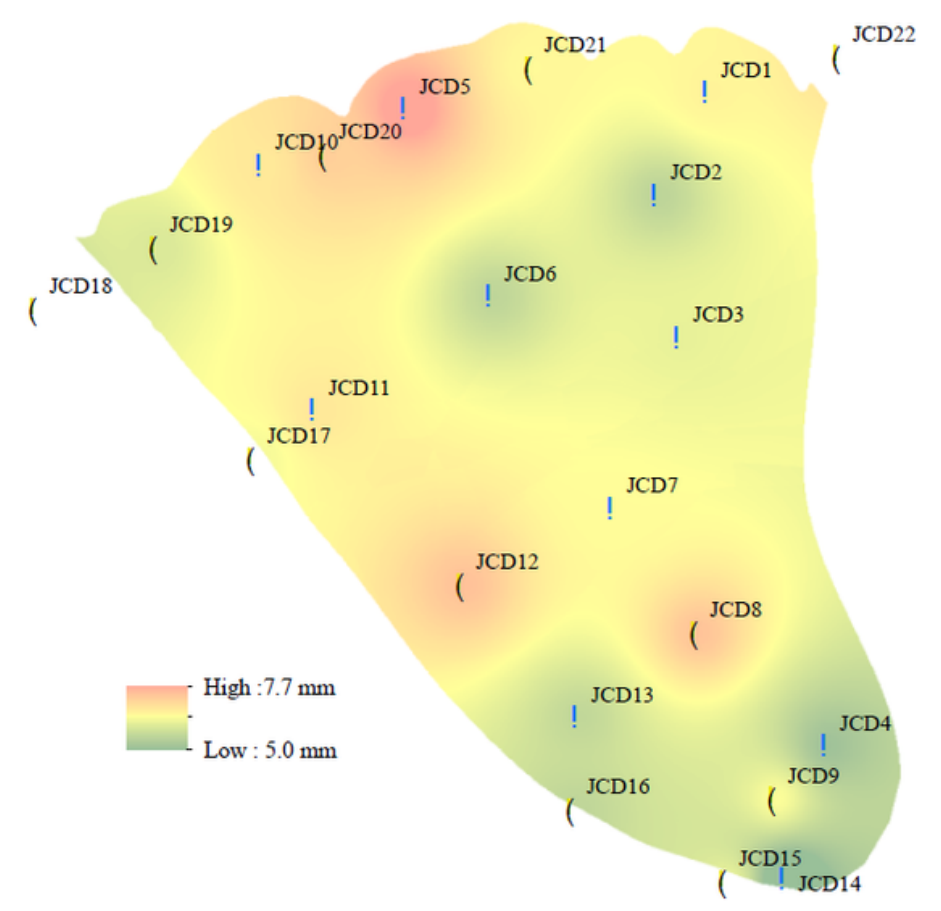

(b) Reservoir water rises by $6 \sim 23 \mathrm{~m}$

Figure 10 
Superposition of bank slope deformation and community detection results of reservoir water level raise

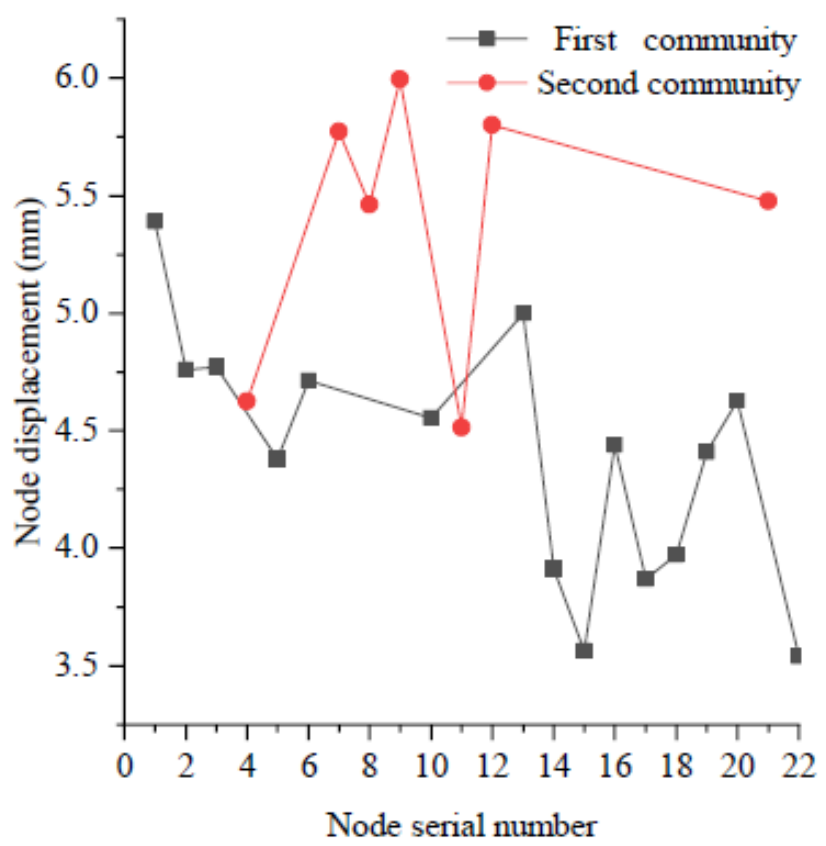

(a) Reservoir water rises by $0 \sim 6 \mathrm{~m}$

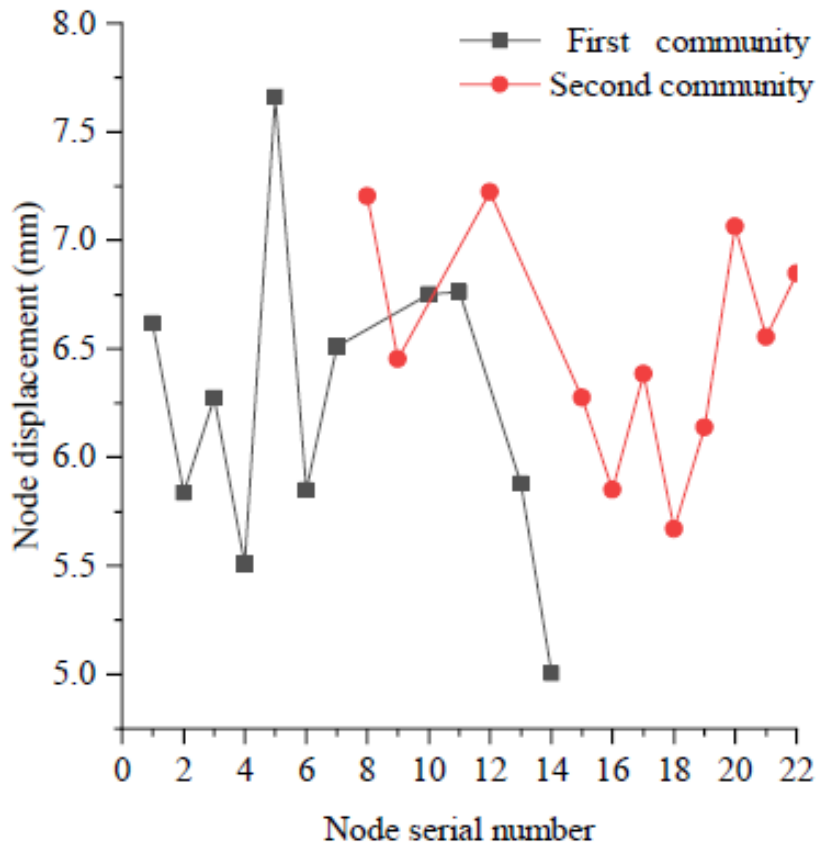

(b) Reservoir water rises by $6 \sim 23 \mathrm{~m}$

\section{Figure 11}

Average displacement diagram of monitoring points for reservoir water level raise

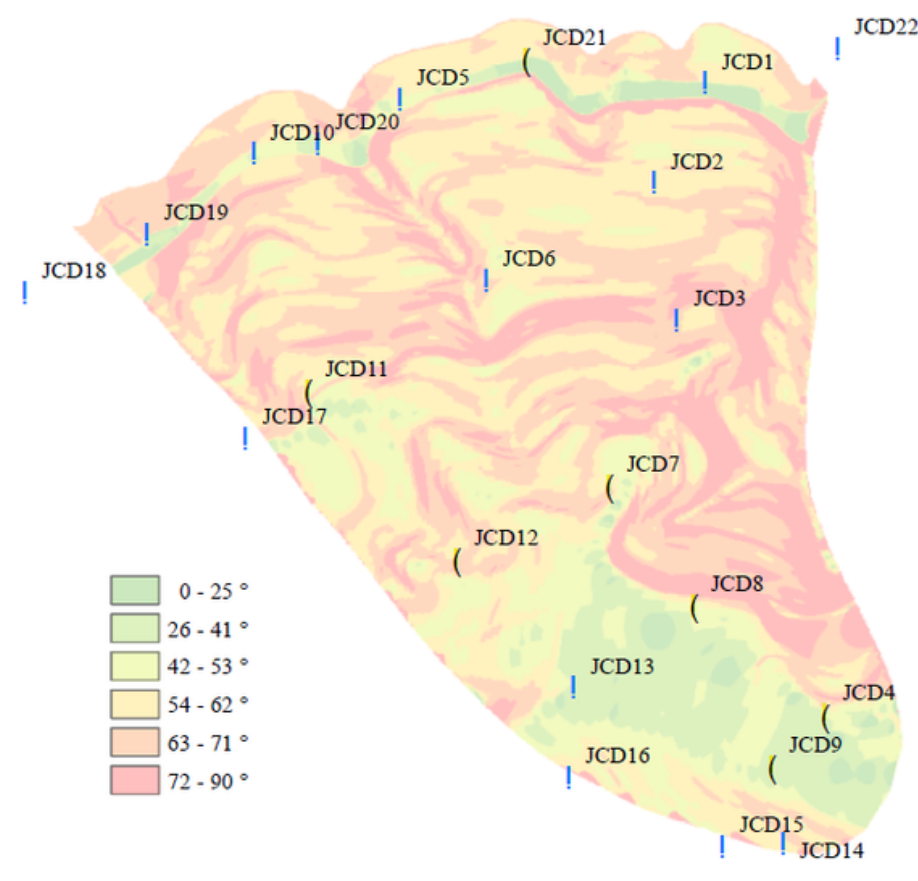

(a) Reservoir water rises by $0 \sim 6 \mathrm{~m}$

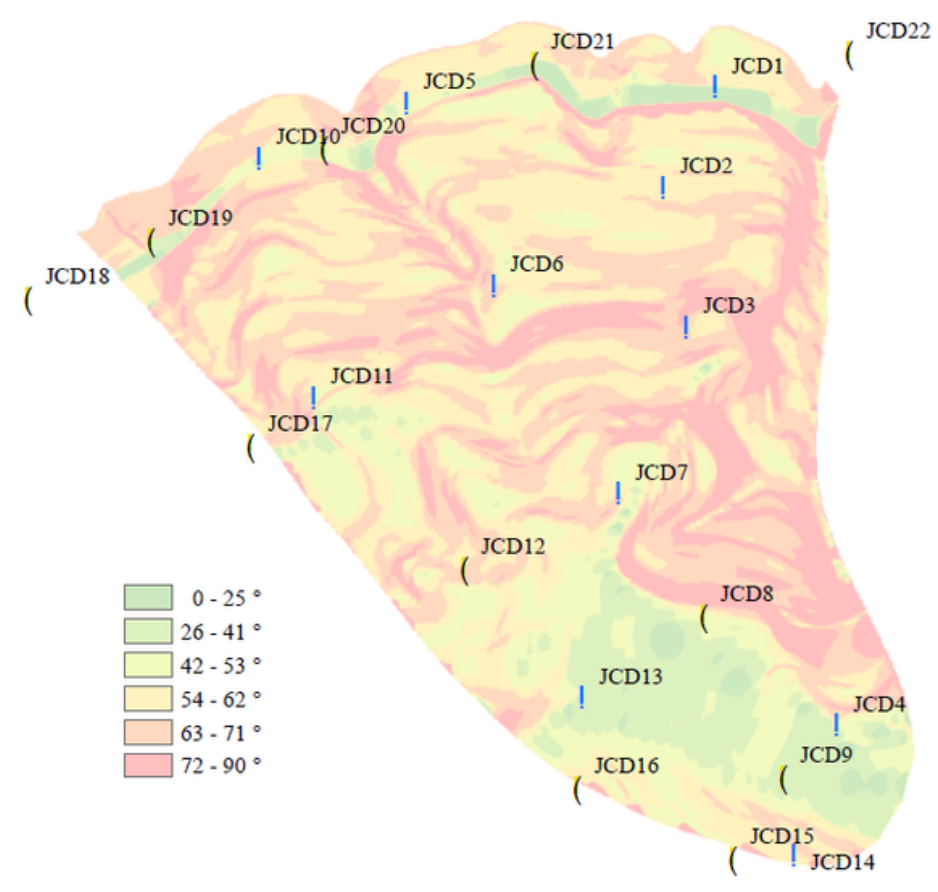

(b) Reservoir water rises by $6 \sim 23 \mathrm{~m}$

Figure 12 
Superposition diagram of raise slope of reservoir water level and detection results 